\title{
HYBRID MODULAR MULTILEVEL CONVERTER FOR VECTOR-CONTROLLED INDUCTION MOTOR DRIVE
}

\author{
${ }^{*}$ Ahmed K. Hannan ${ }^{1}$
}

1) M.Sc., Student Electrical Engineering Department, Mustansiriyah University, Baghdad, Iraq.

2) Assistant Prof., Electrical Engineering Department, Mustansiriyah University, Baghdad, Iraq.
Dr. Turki K. Hassan²

\begin{abstract}
Application of traditional modular multilevel converter (MMC) for medium voltage induction motor drive is difficult especially at low frequencies of drive due to large peak to peak ripple of sub-module (SM) capacitor voltage. In this paper, a hybrid MMC is used to obtain lower peak-to-peak capacitor voltage ripple, specifically at low motor speed. Field oriented control strategy for induction motor created on closed-loop speed controller is suggested to have an accurate and wide speed range of speed. The Matlab/Simulink is used for simulation, the simulation results of induction motor drive with hybrid and traditional MMC are obtained and compared from the point of view of capacitor voltage ripple. The results show the reduction voltage ripple of SM capacitor as the hybrid MMC is operated.
\end{abstract}

Keywords: medium voltage induction motor, Hybrid strategy, lower motor speed, voltage ripple of capacitor, field oriented vector control

\section{Introduction}

Modular multilevel converter (MMC) has got a lot of interest in high-power medium-voltage applications in the last years, due to their modularity, scalability, transformer-less operation, low harmonics, low expense of redundancy, high efficiency, low device switching frequency, reduce filter requirement and quality output waveforms, etc. [1-7].There are four kinds of multilevel inverter topologies: cascade H-bridge (CHB), flying capacitor (FC), neutral point clamped (NPC), and modular multilevel converter [8]. As shown in "Fig. 1", the MMC is consisted of Series connection of sub-modules making the arm of the converter to build the output voltage stepwise.

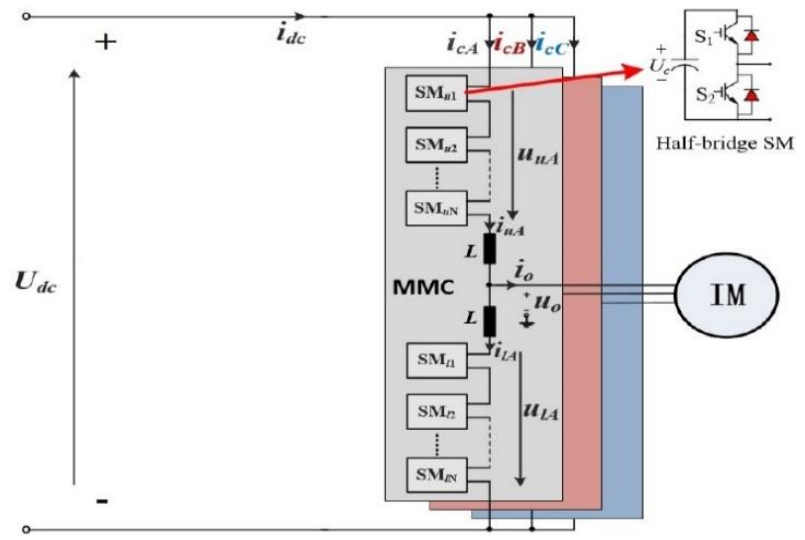

Figure 1. MMC circuit configuration in variable speed drives [8].

Due to the simple structure and modular construction, MMC has used with medium voltage and high-power variable speed drives as a viable solution in recent years. However, the biggest problem for MMC drives is that the SM capacitor voltage ripple peak-to-peak value increases with constant load at low speeds, so it 
is especially challenging for MMC to drive the motor at constant torque at low speeds [9]. The MMC is acceptable to the load torque that is compatible with a square with rotational speeds such as pumps and fans [10]. In order to overcome motor static frictions a high starting torque is needed. Therefore, steps are necessary to minimize the SM capacitor peak-to-peak voltage ripples to provide appropriate torque at low speed ranges. The most efficient method to minimize the capacitor voltage ripple peak-topeak at the moment is injection of high frequency circulating current through MMC arms, in comparison with the same frequency commonmode voltage on the three phase ac terminals [1120]. It is possible to charge and discharge the SM capacitors continuously to minimize the peak-topeak voltage ripple due to a high frequency power transfer between the MMC arms, this caused by the injected voltage and current. Sinusoidal circulating current and commonmode voltage are injected. While it is also possible to use the square wave-forms [16-19], or the Coordination of the third-order current harmonic [20] to minimize the magnitude of the circulating current to minimize losses. But these methods have disadvantages and the following limitations:

- It is so difficult to control and inclusion of the injected common-mode voltage and circulating current waveforms, and the control loops of the MMC (like the voltage balancing and the output current control [10]) can conflict, this causes problems of instability, particularly at transient operations.

- The MMC arms are injected with high values of circulating current, which increases both load current and power losses significantly, thus higher cooling requirements are necessary.

This paper suggests a hybrid MMC strategy that connects between the DC-link and the traditional
MMC by adding a series switch between them, to reduce the above limits of the traditional MMC in variable-speed drive applications. Due to this strategy, the peak-to-peak capacitor voltage ripple can be minimized, especially at low frequencies, this major advantage of hybrid MMC. In addition, the common-mode voltage does not apply on the motor terminals. As well as the load current that remains with the rated value for the entire speed range. So, the suggested hybrid MMC is suitable for variable-speed drive applications. In this paper, the hybrid MMC is used to drive the medium voltage induction motor. Field oriented vector control strategy for induction motor is suggested to get precise speed control. Lower peak-to-peak ripple of (SM) capacitor voltage is noted when hybrid MMC is used compared with traditional MMC.

\section{The Hybrid MMC: Analysis And Operation}

\subsection{The Hybrid MMC Strategy}

The suggested hybrid MMC circuit configuration as shown in "Fig. 2". A series switch $\mathrm{S}_{\mathrm{S}}$ is added between the dc voltage source and MMC converter. This series switch can be used to connect or disconnect the MMC converter from dc source. As this series switch can be used either IGBT or thyristor. In addition, it is necessary to filter the harmonics of the voltage switching, therefor an RC snubber circuit is required [21]. Two grounding resistors $\mathrm{Rg}$ for grounding the converter.

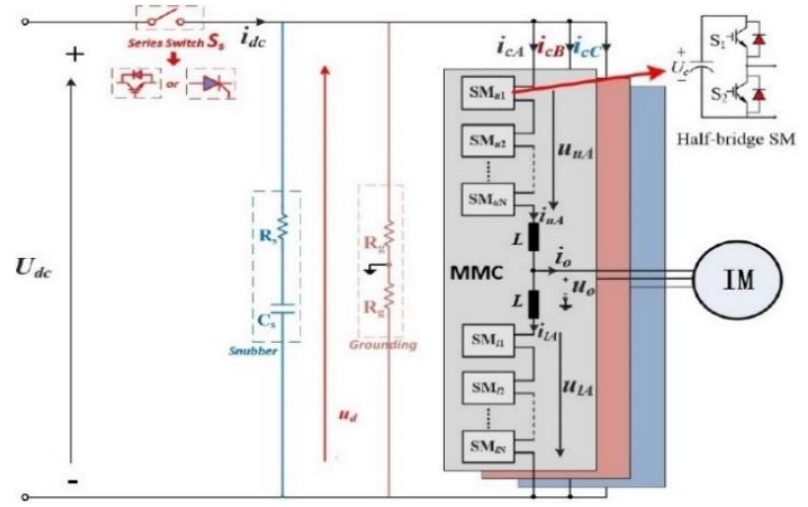

Figure 2. Hybrid MMC circuit configuration in variable speed drives [8]. 
The voltage relationships exist under Kirchhoff's Voltage Law:

$u_{o}=\frac{1}{2}\left(u_{l}-u_{u}-L \frac{d i_{o}}{d t}\right)$

$u_{d}=u_{l}+u_{u}+2 L \frac{d i_{c}}{d t}$

Where $i_{c}$ is the circulating current per phase. It can be calculated by:

$i_{c}=\frac{1}{2}\left(i_{u}+i_{l}\right)$

By summation of the circulating current in each phase the dc current $i_{d c}$ can be calculated. The ac output current $i_{o}$ of MMC would be split equally between these two arms and the arm currents can be written as:

$\left\{\begin{array}{l}i_{u}=i_{c}+(1 / 2) i_{o} \\ i_{l}=i_{c}-(1 / 2) i_{o}\end{array}\right.$

The ac output voltage and current can be expressed as:

$u_{o}=U_{O M} \cos (\omega t)$

$i_{o}=I_{O M} \cos (\omega t-\varphi)$

Where $U_{O M}$ and $I_{O M}$ are the amplitudes, $\varphi$ is the phase lag angle. $\omega$ is the angular frequency, and the amplitude of the output voltage $U_{O M}$ can be written as:

$U_{O M}=1 / 2 m U_{d c}$

Where $m$ represents the modulation index adjusting between 0 to 1 . If the converter is used in variable-speed drives, thus a constant Volt/Hertz ratio must be achieved. If the motor operates at rated speed $\omega_{\text {rated }}, m=1$, an adjustable motor speed modulation index can be determined as:

$m=\frac{\omega}{\omega_{\text {rated }}}$

The operating of hybrid MMC is same as the traditional MMC when the series switch $\mathrm{S}_{\mathrm{S}}$ is closed, $u_{d}$ equals $U_{d c}$. The average voltages of the arm can be estimated by:

$u_{u}=1 / 2 U_{d c}(1-m \cos (\omega t))$

$u_{l}=1 / 2 U_{d c}(1+m \cos (\omega t))$

"Fig. 3", clarifies the traditional MMC main waveforms with suitable harmonic minimization control [22], $i_{c}$ and $i_{d c}$ are dc currents, with the magnitudes of $I_{d c} / 3$ and $I_{d c}$, respectively. Based on the power balance between input $\mathrm{dc}$ and output ac (i.e., $U_{d c} I_{d c}=\frac{3}{2} U_{O M} I_{O M} \cos \varphi$ ), $I_{d c}$ can be expressed as:

$I_{d c}=3 / 4 m I_{O M} \cos \varphi$

When $(m=1)$ the motor at rated speed with rated output current then "(9)" can be written as:

$$
I_{d c \text { (rated })}=3 / 4 I_{O M(\text { rated })} \cos \varphi
$$

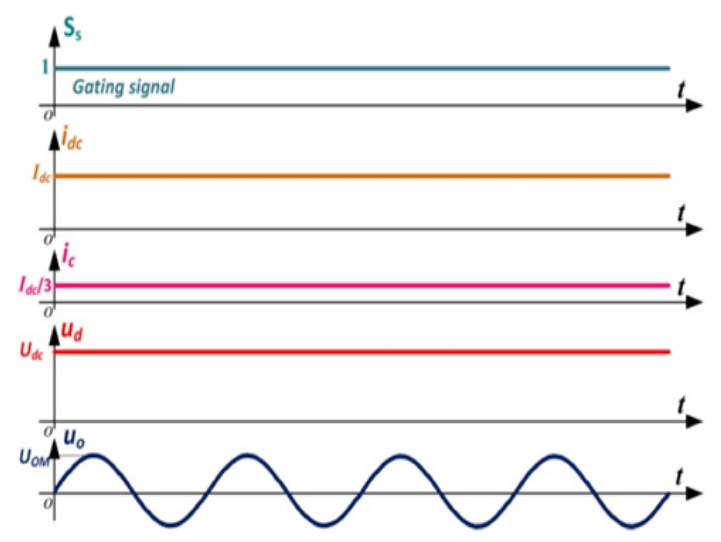

Figure 3. Sketch map of traditional MMC operating waveforms.

\subsection{Operation Principle of Hybrid MMC}

As shown in "Fig. 4", the series switch Ss operates at switching frequency of $f_{h}\left(f_{h}=\right.$ $1 / T_{h}$ ) with duty cycle $D$, the currents $i_{d c}$ and $i_{c}$ are written as:

$I_{d c}=\left\{\begin{array}{ll}I_{d c}(\text { rated }), & \text { if }\left(S_{S}=1\right) \\ 0, & \text { if }\left(S_{s}=0\right)\end{array}\right.$ and $i_{c}=\frac{1}{3} i_{d c}$

Based on "(6)", $u_{d}$ can then be represented as:

$u_{d}=\left\{\begin{aligned} U_{d c}, & \text { if }\left(S_{s}=1\right) \\ m U_{d c}, & \text { if }\left(S_{s}=0\right)\end{aligned}\right.$ 
And the average voltage of $u_{d}$ is

$$
\bar{U}_{d}=D U_{d c}+(1-D) m U_{d c}
$$

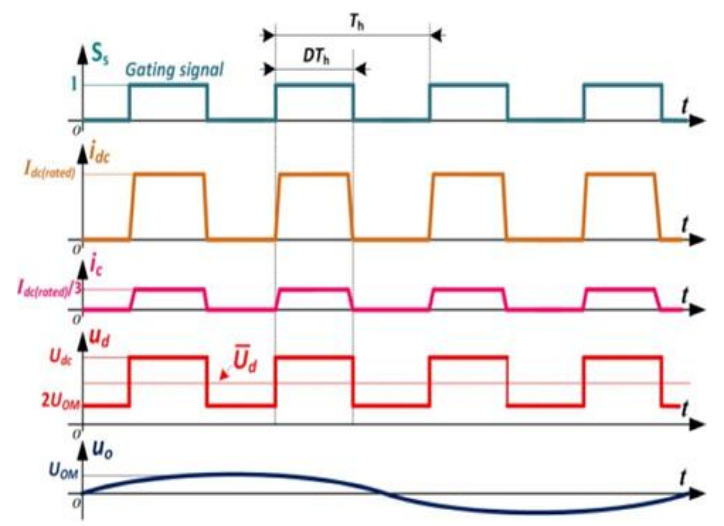

Figure 4. Schematic map of hybrid MMC operating waveforms.

The hybrid MMC arms voltages can expressed as:

$\left\{\begin{array}{l}u_{u=1 / 2} u_{d}-1 / 2 m U_{d c} \cos (\omega t)-\Delta u_{d} \\ u_{l=1 / 2} u_{d}+1 / 2 m U_{d c} \cos (\omega t)-\Delta u_{d}\end{array}\right.$

As comparing "(8)" with "(14)" the ac voltage component does not change at the arm voltage. Applied "(14)" into "(2)" to calculate $\Delta u_{d}$

$L \frac{d i_{c}}{d t}=\Delta u_{d}$

Where $\Delta u_{d}$ is used for controlling of the current circulating $i_{c}$. Despite of this current controllability, the $\mathrm{S}_{\mathrm{S}}$ series switch will achieve zero-current switching. It is necessary to achieve the power balance in the hybrid MMC, which gives:

$$
U_{d c} I_{d c(\text { rated })} D=\frac{3}{2} U_{O M} I_{O M} \cos \varphi
$$

If the motor operates at rated of speed power then $D$ is equal 1 , but other speeds $D$ can be written as:

$D=\frac{m I_{O M}}{I_{O M(\text { rated })}}$

If a constant load is applied at the motor then $\left(I_{O M}=I_{O M(\text { rated })}\right)$. So "(17)" can be simplified to

$D=m$
The peak-to-peak value of the capacitor voltage of the hybrid MMC in [8] can be expressed as:

$\Delta U_{C(p p)}=\left(2-\frac{\omega}{\omega_{\text {rated }}}\right) \frac{I_{O M(\text { rated })}}{2 \omega_{\text {rated }} C}$

Where $C$ represents capacitance value of SM. Thus, the traditional MMC peak-to-peak capacitor voltage ripple can be obtained by [19]:

$\Delta U_{C(p p)}=\frac{I_{O M}}{2 \omega C}$

\section{Control Scheme}

The control scheme is suitable for the suggested hybrid MMC to fed the drive the motor based on Field-oriented control (FOC), can be divided into four main blocks, (A) the series switch control block, (B) the energy balancing control block and (C) Induction motor FOC block (D) the phaseshifted carrier PWM(PSC-PWM). The overall diagram of the control system is shown in "Fig. 5", [23].

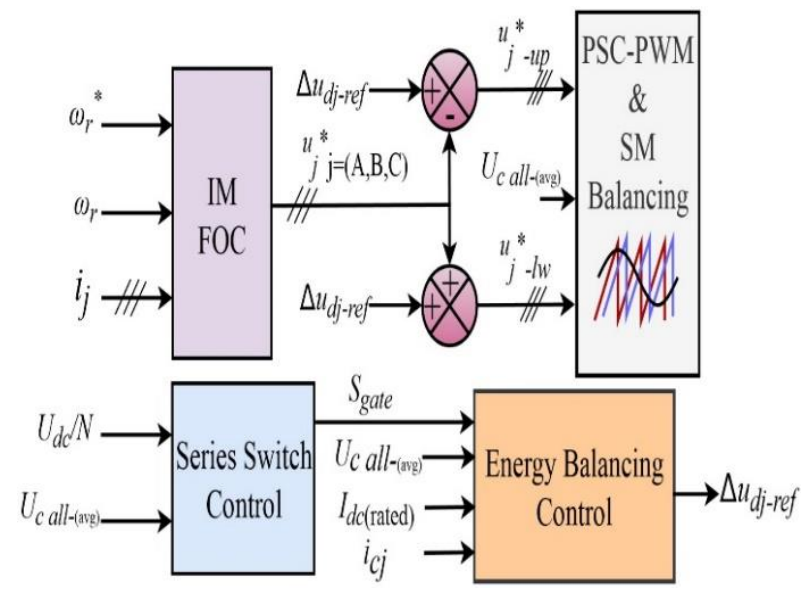

Figure 5. The overall diagram of the control system [23].

\subsection{Series switch control block:}

Series switch control block is shown in "Fig. 6", this block used to adjust the duty cycle $D(D=$ $0 \sim 1$ ) to achieve the balancing of power between the input dc and output ac by using PI controller. When the balance is obtained, the nominal voltage must be equal to $U_{d c} / N$ for all SM capacitors in each phase. The frequency of the carrier $f_{h}$ is 10 times of the output frequency $f_{o}$, and the generated duty cycle signal $S_{\text {gate }}$ is 
applied to the energy balancing control block and the series switch [23].

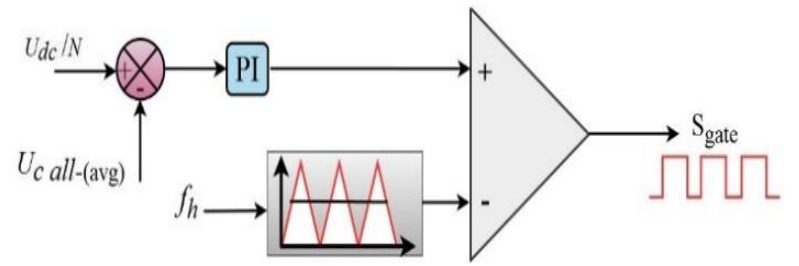

Figure 6. The series switch control [23].

\subsection{Energy balancing control block:}

The energy balancing control is shown in "Fig. 7", a phase energy balance control is implemented in this block in order to ensure equal energy distribution in each phase. The average capacitor voltage of each phase $U_{C(a v g-j)}$ must be equal to $U_{C(a v g)}$ to obtain an adjusting component current $\Delta I_{c j}$. This current is added with $1 / 3 I_{d c \text { (rated) }}$ to produce the $I_{c-r e f}$. The duty cycle $D$ is multiplied with $I_{c-r e f}$ to obtain the circulating current reference. The purpose of this process is to make the actual circulating current to track the $I_{c-r e f}$. Thus, the controlled variable is $\Delta u_{d}$.

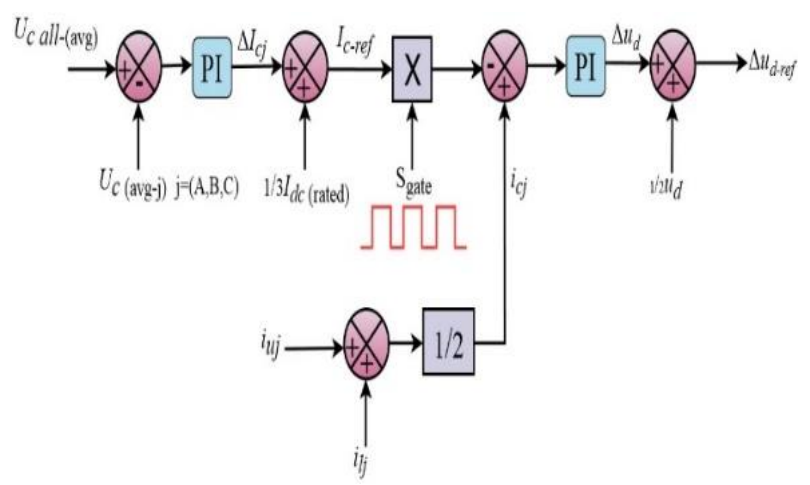

Figure 7. Circulating current control [8].

\subsection{IM FOC BLOCK}

Field-oriented control is a high-efficiency control strategy that similar to the DC machine speed control system [24]. As shown in Fig.8 the FOC block of IM include speed and torque controller loops. And they are applied in the $d$ - $q$ coordinate system. The model equations are listed in [25]. Where $i_{q}$ and $i_{d}$ are the stator currents, and $\omega_{r}$ is the rotor frequency. $\omega_{s}$ and $\psi_{r}$ are respectively stator current frequency and rotor flux, and they can be determined as:

$$
\begin{aligned}
& \psi_{r}=\frac{L_{m}}{T_{r} P+1} i_{d} \\
& \omega_{s l}=\frac{L_{m} i_{q}}{T_{r} \Psi_{r}} \\
& \theta=\int \omega_{s} d_{t}
\end{aligned}
$$

Where $L_{m}$ is the mutual inductance between the stator and rotor, $T_{r}$ is the time constant $\left(T_{r}=\right.$ $\left.L_{r} /_{R_{r}}\right), L_{r}$ and $R_{r}$ are the rotor inductance and the rotor resistance respectively, $p$ is the differential operator and $\theta$ is the rotor angle. FOC of IM block include of four controller loops: flux controller loop to obtain $i_{d}^{*}, i_{d}$ controller loop that is useful to control the excitation of motor, speed controller loop to obtain $i_{q}^{*}$ and $i_{q}$ controller loop is compatible with the output torque.

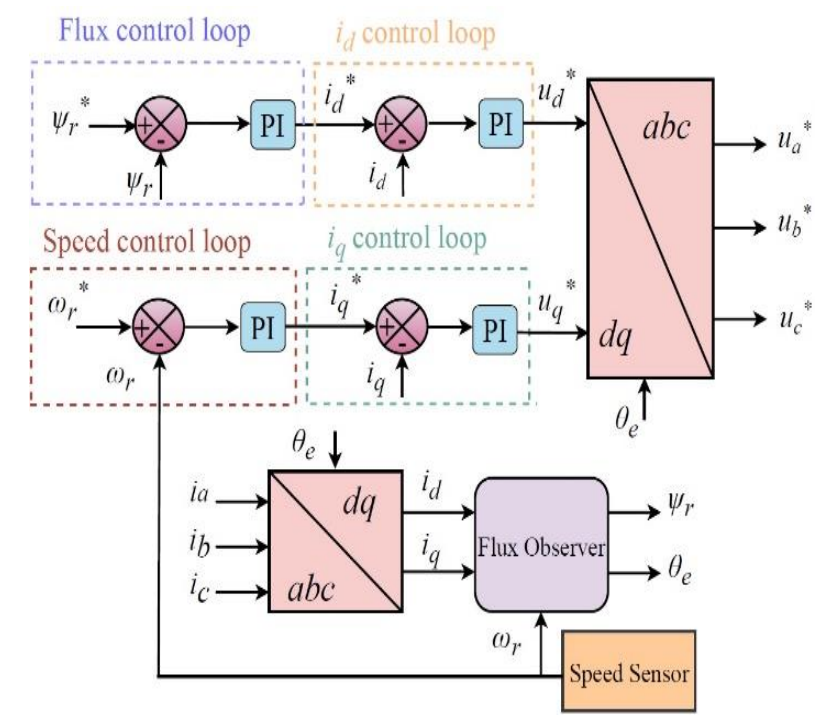

Figure 8. IM FOC block [26].

Finally, references $u_{u j}^{*}$ and $u_{l j}^{*}$ in "Fig. 5", are applied to the phase-shifted carrier PWM (PSCPWM) to build the output voltage stepwise [27]. Also, the other modulation strategies of the MMC are presented in [3]. The purpose of using phase-shifted carrier PWM (PSC-PWM) to improve the equivalent switching frequency and minimize the harmonics of output voltage. 


\section{Simulation And Results}

In order to verify the efficiency of the suggested hybrid MMC-fed IM drive shown in "Fig. 9", a $4160 \mathrm{~V} 1 \mathrm{MW}$ hybrid MMC is simulated by using the MATLAB /Simulink software 2018. The hybrid MMC is implemented with twenty submodules (SMs) per phase. The parameters of the hybrid MMC and IM are listed in "Table 1". The suggested hybrid MMC is simulated in three states in order to show the difference reduction of the peak-to-peak SM capacitor voltage ripple between the traditional MMC and suggested hybrid MMC with variable-speed motor drive. The first state is performed at full speed and constant applied load torque, the second state is performed at constant applied load torque at medium speed with traditional MMC and hybrid $\mathrm{MMC}$, and the final state is performed at low

Table 1. Parameters of drive system

\begin{tabular}{cc}
\hline \multicolumn{2}{c}{ Hybrid MMC parameters } \\
\hline Parameters & Value \\
\hline Number of SMs per arm N & 10 \\
DC-source voltage $U_{d c}$ & $7 \mathrm{kV}$ \\
Nominal SM capacitor voltage $U_{C}$ & $700 \mathrm{~V}$ \\
SM capacitance $C_{S M}$ & $4000 \mu \mathrm{F}$ \\
Arm inductance $L$ & $1 \mathrm{mH}$ \\
Rated output frequency $f_{o(\text { rated })}$ & $60 \mathrm{~Hz}$ \\
Rated phase current $\mathrm{I}_{\mathrm{OM}}$ & $212 \mathrm{~A}$ \\
PSC-PWM frequency $f_{c}$ & $1 \mathrm{kHz}$ \\
S switching frequency $f_{h}$ & $10 \times f_{o}$ \\
Snubber resistance & $200 \Omega$ \\
Snubber capacitance & $1 \mu \mathrm{F}$ \\
\hline IM parameters & \\
\hline Parameters & $\mathrm{Value}$ \\
\hline Rated active power $P_{s}$ & $1250 \mathrm{hp}$ \\
Number of pole pairs $p p$ & 3 \\
Rated speed $\omega_{r}$ & $1200 \mathrm{rpm}$ \\
Rated line-to-line voltage $U_{\text {rated }}$ & $4160 \mathrm{~V}$ \\
Stator rms current $I_{s}$ & $150 \mathrm{~A}$ \\
Power factor cos $\varphi$ & 0.968 \\
Mechanical load torque $T_{\text {rated }}$ & $7490 \mathrm{~N} \cdot \mathrm{m}$ \\
Stator Flux linkage $\psi_{s}$ & $9 \mathrm{~Wb}$ \\
Rotor Flux linkage $\psi_{r}$ & $8.35 \mathrm{~Wb}$ \\
Stator resistance $R_{s}$ & $0.21 \Omega$ \\
Rotor resistance $R_{r}$ & $0.146 \Omega$ \\
Stator leakage inductance $L_{l s}$ & $5.2 \mathrm{mH}$ \\
Rotor leakage inductance $L_{l r}$ & $5.2 \mathrm{mH}$ \\
Magnetizing Inductance $L_{m}$ & $155 \mathrm{mH}$ \\
Moment of Inertia $J$ & $47.6 \mathrm{~kg} \cdot \mathrm{m}^{2}$ \\
\hline
\end{tabular}

speed with traditional MMC and hybrid MMC at constant applied load torque.

The simulation model of hybrid MMC is shown below.

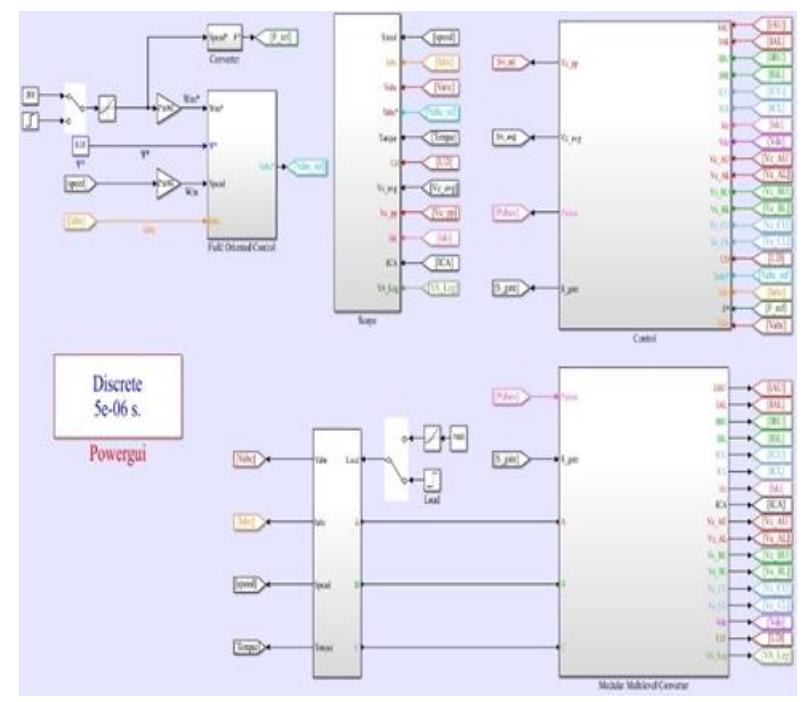

Figure 9. The simulation model of hybrid MMC.

\section{State 1:}

In this state proposed hybrid MMC is operated as a traditional MMC, the IM is operated with rated speed of $1200 \mathrm{rpm}$ and the load torque increases from zero to $7490 \mathrm{~N} \cdot \mathrm{m}$ at time of 2 second from instant of starting. "Fig. 10 (a) ", and "Fig. 10 (b) ", shows the load torque of the motor and the applied load. The motor torque has above of 2000 $\mathrm{N} \cdot \mathrm{m}$ to overcome the moment of inertia of the motor. As it can be shown in the "Fig. 10 (c) ", the stator currents increase to its rated value of $212 \mathrm{~A}$ when the motor load torque rises to its rated value of $7490 \mathrm{~N} \cdot \mathrm{m}$, and the nominal capacitor voltages $u_{c A u} u_{c A l}$ value of $700 \mathrm{~V}$ with a peak-to-peak ripple of $35 \mathrm{~V}$ the capacitor voltage ripple is increase to $55 \mathrm{~V}$ due to increase the output current as shown in "Fig. 10 (d) ". The controller modifies the magnetic current $i_{d}$, while the current $i_{q}$, component tunes the load torque and has an equal to applied load torque value as shown in "Fig. 10 (e) ". The output voltage of the converter keeps at a rated frequency to set the motor desired speed as shown in "Fig. 10 (f) ". 

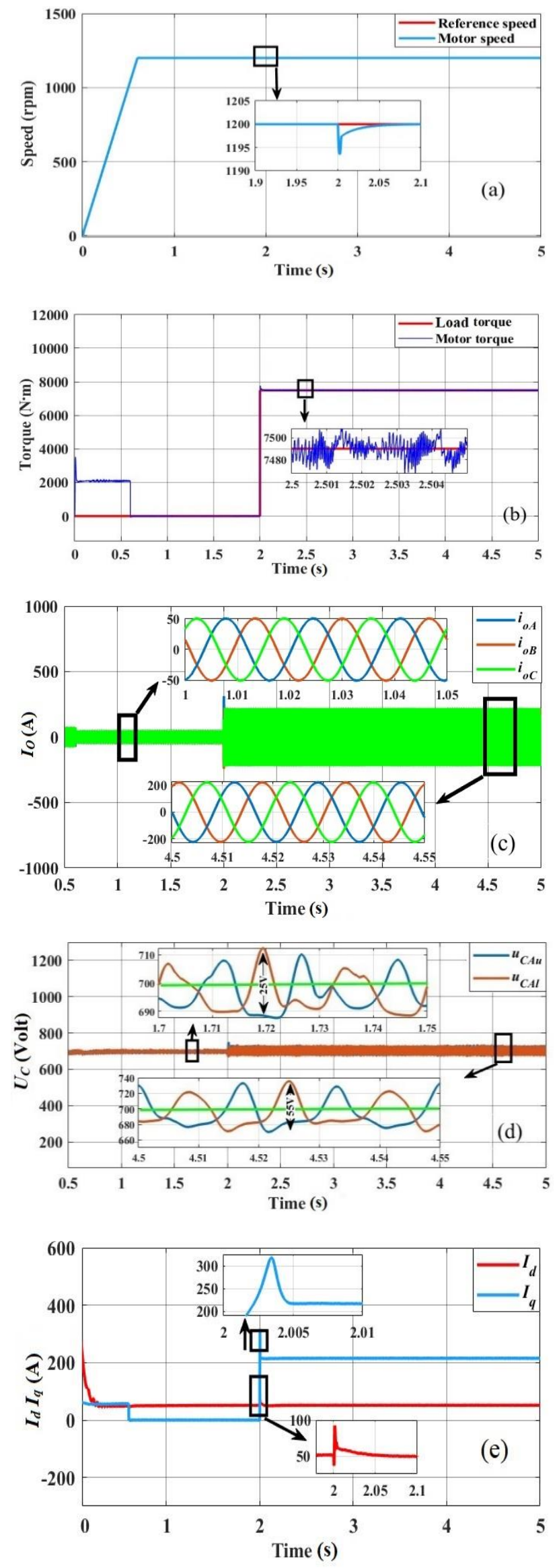

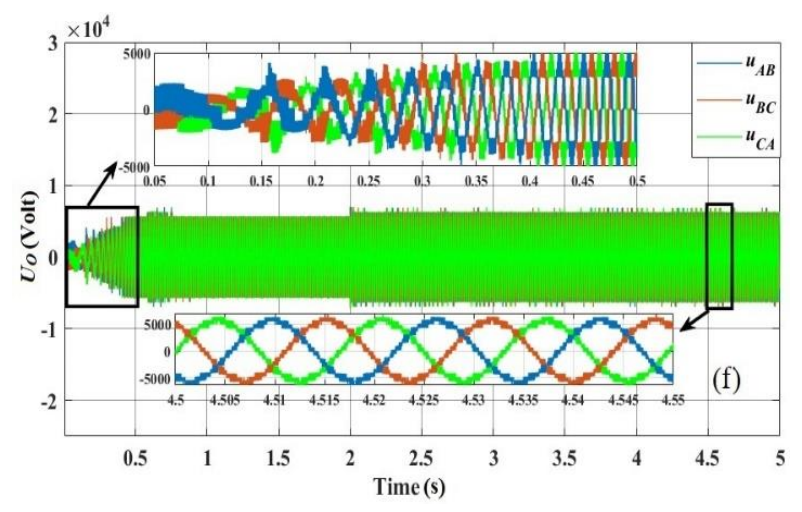

Figure 10. Simulation results of traditional MMC to drive the IM at full speed of $1200 \mathrm{rpm}$ with sudden load torque: (a) Motor speed; (b) load torque of the motor; (c) threephase motor stator currents; (d) SM capacitor voltages per phase; (e) $I_{d}, I_{q}$ current component of the motor; (f) output voltages of the converter.

\section{State 2:}

In this state the MMC is operated as a traditional MMC and a hybrid, the IM is operate with medium speed of $600 \mathrm{rpm}$ and the load torque increases from zero to $7490 \mathrm{~N} \cdot \mathrm{m}$ at 2 second from instant of starting. "Fig. 11 (a) ", and "Fig. 11 (b) ", shows a good speed and torque dynamic response when the applied load is changed. As it can be shown in the "Fig. 11 (c) ", that the stator currents are sinusoidal waveforms with highquality with amplitude of 50A, and increase to its rated value of $212 \mathrm{~A}$ when the motor load torque rises to its rated value of $7490 \mathrm{~N} \cdot \mathrm{m}$, and the nominal capacitor voltages $u_{c A u} u_{c A l}$ of hybrid MMC with value of $700 \mathrm{~V}$ with a peak-to-peak ripple of $35 \mathrm{~V}$ and increased to $70 \mathrm{~V}$ due to increase the output current as shown in "Fig. 11 (d) ". "Fig. 11 (e) ", shows that the nominal capacitor voltages $u_{c A u} u_{c A l}$ of traditional MMC with value of $700 \mathrm{~V}$ with a peak-to-peak ripple of $40 \mathrm{~V}$ and increased to $180 \mathrm{~V}$ due to increase the output current. The controller modifies the magnetic current $i_{d}$, while the current $i_{q}$ component tunes the load torque and has an equal to applied load torque value as shown in "Fig. 11 (f) ". The output voltage of the converter keeps at frequency of $30 \mathrm{~Hz}$ to set the motor desired speed as shown in "Fig. $11(\mathrm{~g})$ ". 

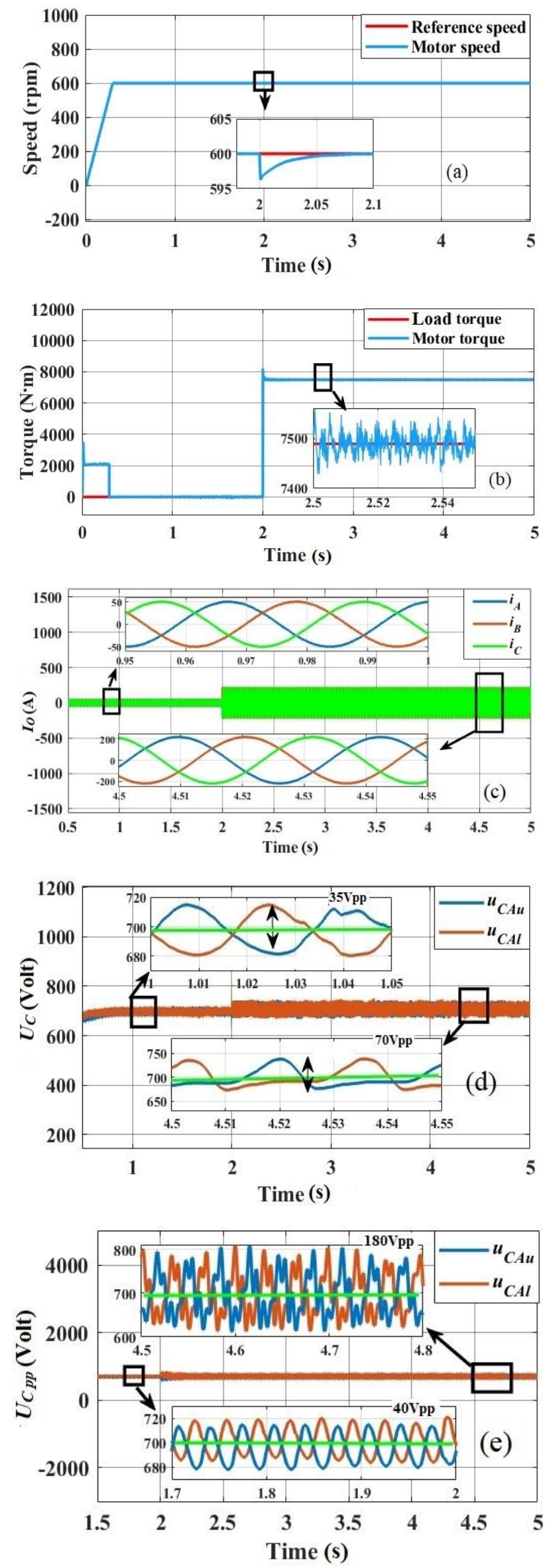
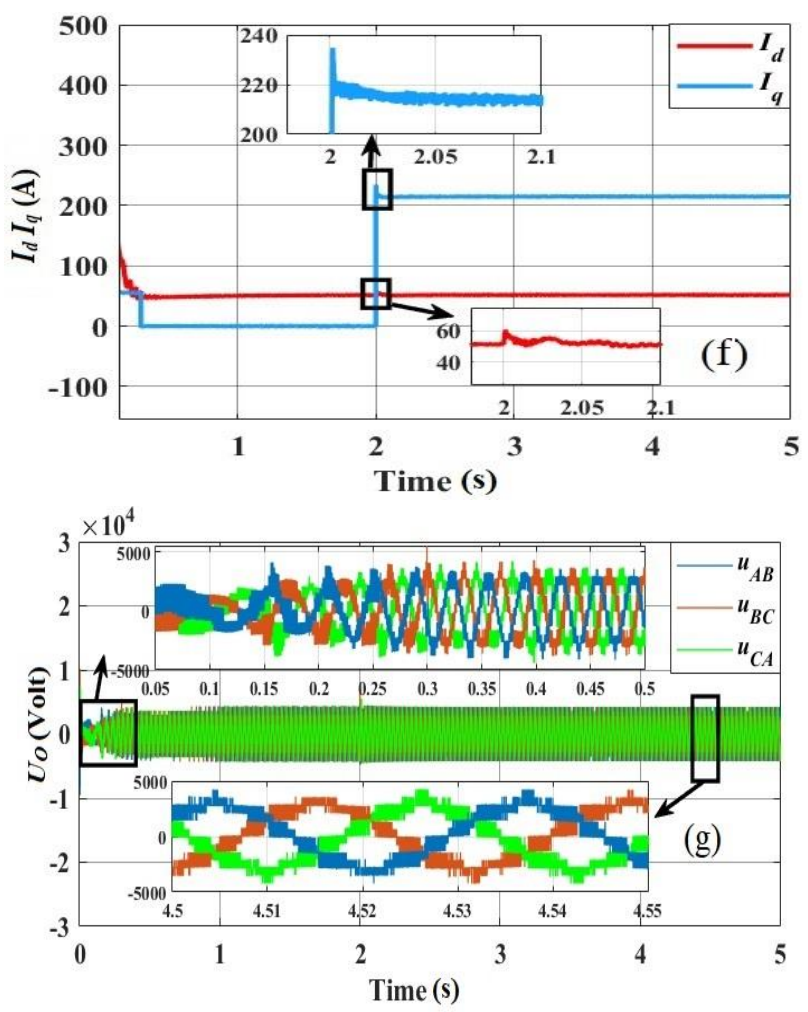

Figure 11. Simulation results of hybrid MMC and traditional to drive the IM at medium speed of 600rpm with sudden load torque: Motor speed; (b) load torque of the motor; (c) three-phase motor stator currents; (d) SM capacitor voltages per phase; (e) SM capacitor voltages per phase of traditional MMC; (f) $I_{d}, I_{q}$ current component of the motor; (g) output voltages of the converter.

\section{State 3:}

In this state the MMC is operated as a traditional MMC and a hybrid, the IM is operate with low speed of $200 \mathrm{rpm}$ and the load torque increases from zero to $7490 \mathrm{~N} \cdot \mathrm{m}$ at 0.2 second from instant of starting. "Fig. 12 (a) ", and "Fig. 12 (b) ", shows a good speed and torque dynamic response when the applied load is changed. "Fig. 12 (c) ", shows the stator currents with high-quality sinusoidal waveforms at low frequency with amplitude of 50A, and increase to its rated value of $212 \mathrm{~A}$ when the motor load torque rises to its rated value of $7490 \mathrm{~N} \cdot \mathrm{m}$. The nominal capacitor voltages $u_{c A u} u_{c A l}$ of hybrid MMC with value of $700 \mathrm{~V}$ with a peak-to-peak ripple of $180 \mathrm{~V}$ due to increase the output current as shown in "Fig. 12 (d) ". "Fig. 12 (e) ", shows that the nominal 
capacitor voltages $u_{c A u} u_{c A l}$ of traditional MMC with value of $700 \mathrm{~V}$ with a peak-to-peak ripple of $410 \mathrm{~V}$ due to increase the output current. The controller modifies the magnetic current $i_{d}$, while the current $i_{q}$ component tunes the load torque and has an equal to applied load torque value as shown in "Fig. 12 (f) ". The output voltage of the converter keeps at frequency of $10 \mathrm{~Hz}$ to set the motor desired speed as shown in "Fig. 12 (g) ".
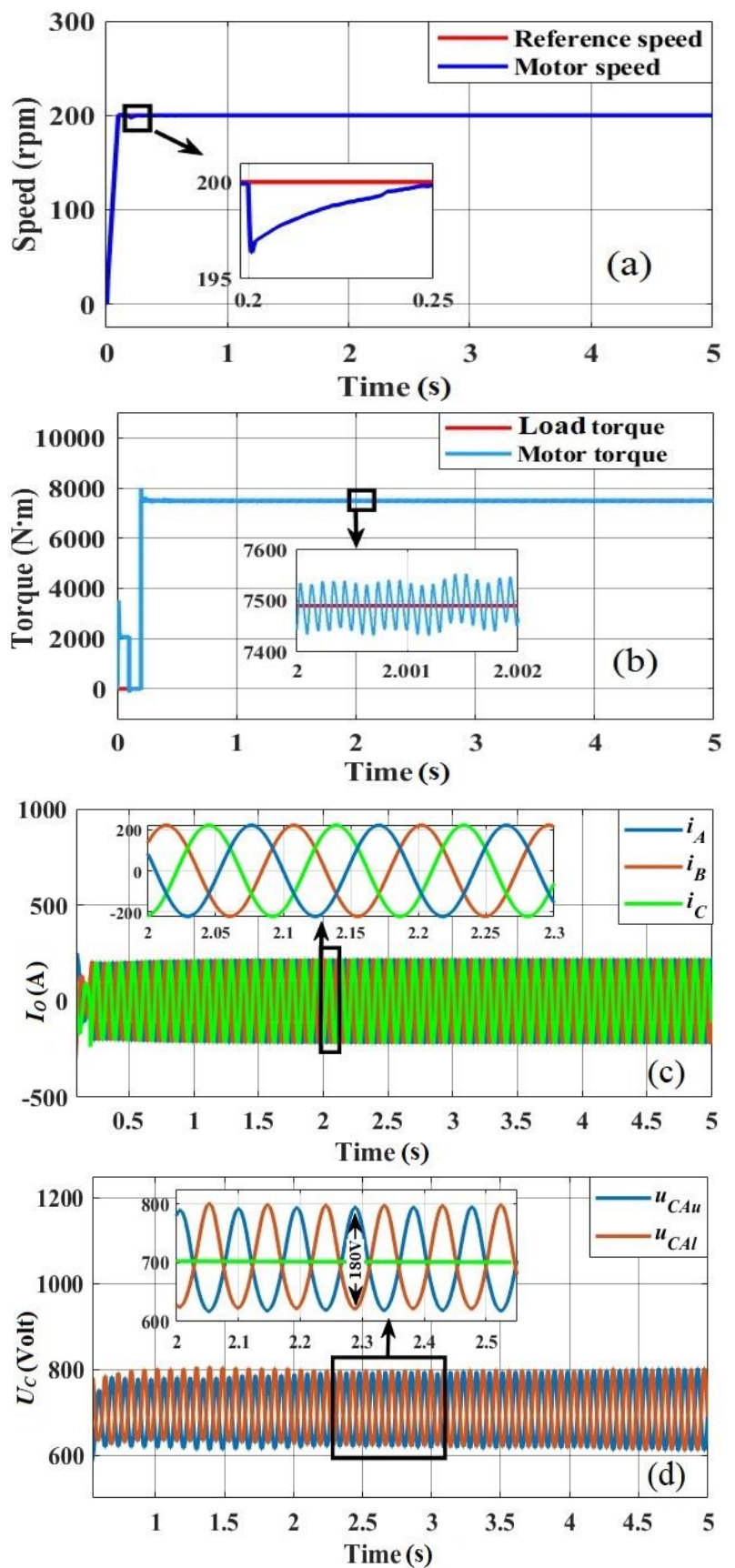
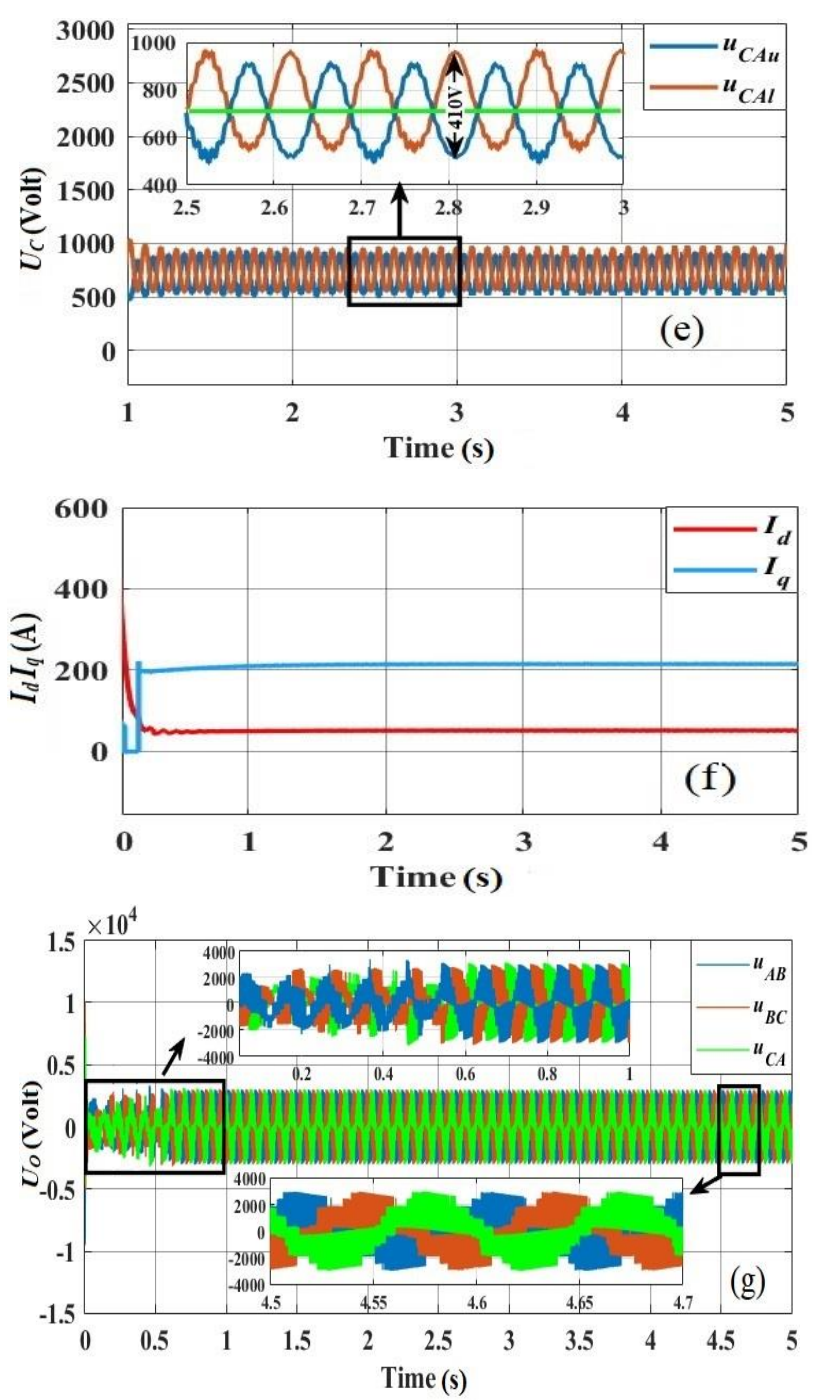

Figure 12. Simulation results of hybrid $M M C$ and traditional to drive the IM at low speed of 200rpm with sudden load torque: Motor speed; (b) load torque of the motor; (c) three-phase motor stator currents; (d) SM capacitor voltages per phase; (e) SM capacitor voltages per phase of traditional MMC; (f) $I_{d}, I_{q}$ current component of the motor; $(\mathrm{g})$ output voltages of the converter

Table 2. Peak-to-peak ripple of SM capacitor voltage

\begin{tabular}{lll}
\hline Speed (rpm) & Traditional MMC & Hybrid MMC \\
\hline $1200 \mathrm{rpm}$ & $55 \mathrm{~V}$ & $55 \mathrm{~V}$ \\
$600 \mathrm{rpm}$ & $180 \mathrm{~V}$ & $70 \mathrm{~V}$ \\
$200 \mathrm{rpm}$ & $410 \mathrm{~V}$ & $180 \mathrm{~V}$
\end{tabular}

Lower values of peak-to-peak ripple in SM capacitor voltage are noticed in hybrid MMC 
compared with traditional MMC as shown in "Table 2".

\section{Conclusions}

This paper suggested hybrid MMC to drive IM. Because of lower peak-to-peak capacitor voltage ripple at low frequency with constant load torque as seen in the simulation results, the suggested hybrid MMC is acceptable for variable-speed drives. This paper suggested a suitable control strategy that Proportional to the variable-speed motor drives. Also, the other advantages of this strategy are that it does not introduce higher switching losses and conduction; it can offer a protection to dc link from short circuit.

\section{Acknowledgements}

This work is supported by Electrical Department/ College of Engineering/ Mustansiriyah University.

\section{Conflict of interest}

The authors whose listed their names in this paper certify that they have no affiliations with or involvement in any organization or entity with any financial interest in the subject matter or materials discussed in this manuscript.

\section{References}

1. A. Lesnicar and R. Marquardt. (2003). "An innovative modular multilevel converter topology suitable for a wide power range," in 2003 IEEE Bologna Power Tech Conference Proceedings, vol. 3, pp. 6-pp.

2. M. Hagiwara and H. Akagi. (2009). "Control and experiment of pulsewidth-modulated modular multilevel converters," IEEE Trans. power Electron., vol. 24, no. 7, pp. 17371746.

3. S. Debnath, J. Qin, B. Bahrani, M. Saeedifard, and P. Barbosa. (2015). "Operation, control, and applications of the modular multilevel converter: A review," IEEE Trans. power Electron., vol. 30, no. 1, pp. 37-53.

4. K. Ilves, L. Harnefors, S. Norrga, and H.-P. Nee. (2014). "Analysis and operation of modular multilevel converters with phaseshifted carrier PWM," IEEE Trans. Power Electron., vol. 30, no. 1, pp. 268-283.

5. M. Saeedifard and R. Iravani. (2010). "Dynamic performance of a modular multilevel back-to-back HVDC system," IEEE Trans. power Deliv., vol. 25, no. 4, pp. 2903-2912.

6. M. T. Bina. (2011). "A transformerless medium-voltage STATCOM topology based on extended modular multilevel converters," IEEE Trans. Power Electron., vol. 26, no. 5, pp. 1534-1545.

7. H.-J. Knaak. (2011). "Modular multilevel converters and HVDC/FACTS: A success story," in Proceedings of the 2011 14th European conference on power electronics and applications, 2011, pp. 1-6.

8. B. Li, S. Zhou, D. Xu, S. J. Finney, and B. W. Williams. (2017). "A Hybrid Modular Multilevel Converter for Medium-Voltage Variable-Speed Motor Drives," IEEE Trans. Power Electron., vol. 32, no. 6, pp. 46194630 .

9. S. Sau and B. G. Fernandes. (2018). "Modular multilevel converter based variable speed drive with reduced capacitor ripple voltage," IEEE Trans. Ind. Electron., vol. 66, no. 5, pp. 3412-3421.

10. M. Hagiwara, K. Nishimura, and $\mathrm{H}$. Akagi. (2010). "A medium-voltage motor 
drive with a modular multilevel PWM inverter," IEEE Trans. Power Electron., vol. 25, no. 7, pp. 1786-1799.

11. J. Kolb, F. Kammerer, M. Gommeringer, and M. Braun. (2015). "Cascaded control system of the modular multilevel converter for feeding variable-speed drives," IEEE Trans. Power Electron., vol. 30, no. 1, pp. 349-357.

12. M. Spichartz, V. Staudt, and A. Steimel. (2013). "Modular multilevel converter for propulsion system of electric ships," in 2013 IEEE Electric Ship Technologies Symposium (ESTS), 2013, pp. 237-242.

13. A. Antonopoulos, L. Ängquist, S. Norrga, K. Ilves, L. Harnefors, and H.-P. Nee. (2013). "Modular multilevel converter ac motor drives with constant torque from zero to nominal speed," IEEE Trans. Ind. Appl., vol. 50, no. 3, pp. 1982-1993.

14. J.-J. Jung, H.-J. Lee, and S.-K. Sul. (2012). "Control of the modular multilevel converter for variable-speed drives," in 2012 IEEE International Conference on Power Electronics, Drives and Energy Systems (PEDES), pp. 1-6.

15. K. Wang, Y. Li, Z. Zheng, and L. Xu. (2013). "Voltage balancing and fluctuationsuppression methods of floating capacitors in a new modular multilevel converter," IEEE Trans. Ind. Electron., vol. 60, no. 5, pp. $1943-$ 1954.

16. M. Hagiwara, I. Hasegawa, and H. Akagi. (2013). "Start-up and low-speed operation of an electric motor driven by a modular multilevel cascade inverter," IEEE Trans. Ind. Appl., vol. 49, no. 4, pp. 1556-1565.
17. Y. Okazaki, M. Hagiwara, and H. Akagi. (2013). "A speed-sensorless start-up method of an induction motor driven by a modular multilevel cascade inverter (MMCI-DSCC)," IEEE Trans. Ind. Appl., vol. 50, no. 4, pp. 2671-2680.

18. J.-J. Jung, H.-J. Lee, and S.-K. Sul. (2015). "Control strategy for improved dynamic performance of variable-speed drives with modular multilevel converter," IEEE J. Emerg. Sel. Top. Power Electron., vol. 3, no. 2, pp. 371-380.

19. B. Li et al. (2016). "An improved circulating current injection method for modular multilevel converters in variablespeed drives," IEEE Trans. Ind. Electron., vol. 63, no. 11, pp. 7215-7225.

20. S. Debnath, J. Qin, and M. Saeedifard. (2015). "Control and stability analysis of modular multilevel converter under lowfrequency operation," IEEE Trans. Ind. Electron., vol. 62, no. 9, pp. 5329-5339.

21. H. Peng, M. Hagiwara, and H. Akagi. (2013). "Modeling and analysis of switchingripple voltage on the DC link between a diode rectifier and a modular multilevel cascade inverter (MMCI)," IEEE Trans. power Electron., vol. 28, no. 1, pp. 75-84.

22. Z. Li, P. Wang, Z. Chu, H. Zhu, Y. Luo, and Y. Li. (2013). "An inner current suppressing method for modular multilevel converters," IEEE Trans. Power Electron., vol. 28 , no. 11, pp. 4873-4879.

23. S. Zhou, M. Guan, B. Li, S. Zhou, and D. $\mathrm{Xu}$. (2017) "Control of the hybrid modular multilevel converter in motor drive 
applications," Conf. Proc. - IEEE Appl. Power Electron. Conf. Expo. - APEC, pp. 666-670.

24. A. M. Nori and T. K. Hassan. (2019). "Modeling and simulation of quasi-Z-source indirect matrix converter for permanent magnet synchronous motor drive," Int. J. Power Electron. Drive Syst., vol. 10, no. 2, pp. 882-899.

25. B. Wu and M. Narimani. (2017). Highpower converters and AC drives. John Wiley \& Sons.

26. M. S. Diab, A. M. Massoud, S. Ahmed, and B. W. Williams. (2019). "A Modular Multilevel Converter with Ripple-Power Decoupling Channels for Three-Phase MV Adjustable-Speed Drives," IEEE Trans. Power Electron., vol. 34, no. 5, pp. 40484063.

27. B. Li, R. Yang, D. Xu, G. Wang, W. Wang, and D. Xu. (2015). "Analysis of the phase-shifted carrier modulation for modular multilevel converters," IEEE Trans. Power Electron., vol. 30, no. 1, pp. 297-310. 